\title{
Multidisciplinary questions in thoracic oncology: the team experience
}

\author{
Jean-Paul Sculier \\ Affiliation: Service des soins intensifs et urgences oncologiques and Oncologie thoracique, Institut Jules \\ Bordet, Université Libre de Bruxelles (ULB), Brussels, Belgium.
}

Correspondence: Jean-Paul Sculier, Service des soins intensifs et urgences oncologiques and Oncologie thoracique, Institut Jules Bordet, Université Libre de Bruxelles (ULB), 1 rue Héger-Bordet, B-1000 Brussels, Belgium. E-mail: sculierabordet.be

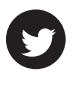

@ERSpublications

Introducing a new $E R J$ series examining the multidisciplinary character of thoracic oncology http://ow.ly/59bY300wrRS

In the context of the European Respiratory Society (ERS) plan for thoracic oncology [1], in 2014 the European Respiratory Journal (ERJ) initiated a series of reviews called "Challenges and controversies in thoracic oncology" [2]. The following questions were addressed. The specific contribution of each thoracic staging and treatment modality has not always been unequivocally established: which grey areas remain? Concerning screening programmes for lung cancer, is it time for large-scale screening via chest computed tomography? Is multidisciplinary team management in thoracic oncology more than a concept? Considering tumour tissue sampling for lung cancer management at the era of personalised therapy, what is enough for molecular testing? Which approaches should be used for small sized lung cancer: lobectomy, sublobectomy or stereotactic irradiation? What is the place of multimodality management of malignant pleural mesothelioma? How can non-inferiority trials influence practice in thoracic oncology without valid conclusions? How should advanced nonsmall cell lung cancer (NSCLC) be treated: by targeted therapy, personalised chemotherapy or standard chemotherapy? What is the exact role of palliative care in the patient's management? What should be the approach to the staging of lung cancer, with regard to noninvasive, minimally invasive and invasive techniques? Which examinations (and at what time) should take place during the follow-up of the patient after lung cancer resection? What is the best management option for a patient with NSCLC, with an epidermal growth factor receptor activating mutation or with an Alk translocation?

It is time to move to another series and the editorial board has decided to ask for reviews on the team experience of multidisciplinary questions in thoracic oncology. Key authors have been asked to develop their point of view with collaborators from other disciplines on a topic which requires a multidisciplinary approach. 12 subjects have been selected: risk factors for lung cancer; lung cancer screening; the lung cancer clinic; molecular biomarkers for lung cancer; lung cancer staging; management of stage I and II NSCLC; management of stage III NSCLC; biological therapies; limited disease small cell lung cancer; comorbidities in the management of lung cancer; pain control; and intensive care in thoracic oncology.

Pneumologists, medical oncologists, thoracic surgeons, radiation oncologists, radiologists, nuclear medicine specialists, epidemiologists, anatomical pathologists, molecular biologists, anaesthesiologists, intensivists and other specialists will contribute to this new series. These reviews will in addition provide support to the new HERMES thoracic oncology programme [3], a collaboration between members of the four main European scientific societies dealing with thoracic oncology: ERS, European Society for Medical Oncology, European Society for Radiotherapy and Oncology, and European Society of Thoracic Surgeons. We are very proud that the $E R J$ contributes to inform our readers about the multidisciplinary character of thoracic oncology by publishing the first article of the new series in this issue [4].

Received: May 102016 | Accepted: May 102016

Conflict of interest: None declared.

Copyright OERS 2016 


\section{References}

1 Sculier JP, Vansteenkiste J, Schönfeld N, et al. Thoracic oncology in Europe: the ERS action plan by the Thoracic Oncology Assembly. Eur Respir J 2010; 36: 1227-1228.

2 Sculier JP, Besse B, Van Schil P. Challenges and controversies in thoracic oncology: a new ERJ series. Eur Respir J 2014; 43: 1571-1572.

3 Gamarra F, Boffetta P, De Ruysscher D, et al. Thoracic Oncology HERMES syllabus: setting the basis for thoracic oncology training in Europe. Eur Respir J 2013; 42: 568-571.

4 Malhotra J, Malvezzi M, Negri E, et al. Risk factors for lung cancer worldwide. Eur Respir J 2016; 48: 889-902. 